\title{
Breu crònica d'un congrés especial, o la celebració de mig segle de Llull a Freiburg (Alemanya)
}

\author{
Josep E. Rubio \\ Universitat de València
}

El «Raimundus-Lullus-Institut» és una d'aqueixes institucions acadèmiques que gaudeixen de prestigi en el seu àmbit concret i que són més reconegudes que conegudes. Una mica el mateix que li esdevé a Ramon Llull, l'autor l'obra llatina del qual s'encarrega d'editar l'institut. Des de terres hispàniques, des de Catalunya mateix, on aquest tipus de centres d'investigació vinculats a una universitat no són tan freqüents, un es pregunta què és exactament el «Raimundus-Lullus-Institut». A mi almenys m'han fet la pregunta moltes vegades: col-legues, estudiants, amics, coneguts, saben que hi vaig sovint, que hi he treballat; saben, fins i tot, que és un centre encarregat de l'edició de l'obra llatina de Llull. Un centre de recerca? A la Universitat de Freiburg? Té aules on es fan classes? Bé, no exactament: no és aqueixa la seva funció, encara que de vegades un es troba que a mitja vesprada una de les sales de la biblioteca és ocupada per un seminari. D'aules no en té, però. És un centre editorial que publica les obres de Llull? Tampoc: és l'editorial Brepols, a la ciutat flamenca de Turnhout, la que s'encarrega d'imprimir els volums de la sèrie ROL («Raimundi Lulli Opera Latina») dintre del «Corpus Christianorum». El «Raimundus-Lullus-Institut» és l'encarregat de coordinar acadèmicament l'elaboració de les edicions crítiques de les obres de Llull que després es publiquen a Bèlgica. Cal doncs treballar i viure a Freiburg, tenir un despatx a l'institut de recerca, ser de la seva plantilla laboral, per editar un volum de les ROL? Tampoc, no cal res d'això. Com és físicament, què i qui hi ha dintre?

Aquestes qüestions me les han fetes moltes vegades. Una manera de trobarne resposta és visitar el centre i veure in situ com és. Alguns que ho han fet han sentit de primer una certa sorpresa per no trobar-se davant un típic departament universitari espanyol ple de despatxos i amb una trentena de professors pul-lulant per passadissos laberíntics. La topografia del «Raimundus-LullusInstitut» és senzilla: un petit espai de recepció que enfronta el depatx de la secretària i els seus ajudants, paral-lel a un petit corridor amb prestatges en el qual s'obrin dos despatxos i que està limitat en els dos extrems per sengles sales més grans, plenes de llibres i de taules de treball. El «Raimundus-LullusInstitut» és un lloc de treball sobre l'obra de Llull, una imponent biblioteca amb gairebé tota la literatura primària i de fonts sobre l'autor, però també sobre 
filosofia, història i teologia medievals. La seva biblioteca serveix també a l'estudi de les fonts de la teologia medieval, com anuncia el segon nom de l'institut: «Quellekunde der Theologie des Mittelalters».

Conèixer el seu mig segle d'història és una altra manera de conèixer l'Institut. Acaba de complir cinquanta anys d'activitat des de la seva fundació, l'any 1957, pel professor de teologia Friedrich Stegmüller. Els seus objectius eren recollir còpies microfilmades de tots els manuscrits lul-lians dispersos en les biblioteques d'arreu del món, classificar-les, centralitzar-les, estudiar-ne el contingut, i oferir així, junt amb una biblioteca amb tot el material bibliogràfic necessari, les eines per tal de procedir a l'edició crítica de l'obra llatina de Llull d'acord amb uns criteris científics. El resultat, en els cinquanta anys de camí i d'adaptació als nous temps i a les noves tecnologies (el «RaimundusLullus-Institut» està procedint a la digitalització dels microfilms i ofereix així la consulta dels manuscrits «on line»), són trenta-dos volums de referència, i alguna cosa més que els volums: estudis sobre l'obra de Llull, estímul a la redacció de tesis doctorals sobre l'autor, tot a recer de l'edició crítica de l'obra llatina. Doctorands de tot el món que volen fer una tesi sobre Llull visiten el «Raimundus-Lullus-Institut» per aprofitar-se'n dels fons. És un centre obert, que ofereix tot el necessari a l'investigador i que orienta des de Freiburg el treball d'edició de l'obra lul-liana, motiu central de la seva existència, als estudiosos que s'hi ocupen i que provenen de diverses universitats europees. I no és sobrer recordar que per la seva aportació a la cultura catalana va estar guardonat amb la Creu de Sant Jordi per la Generalitat de Catalunya.

Per celebrar el cinquanta aniversari, l'Institut ha organitzat els dies 25 a 28 de novembre del passat any 2007 un congrés internacional dedicat a l'anàlisi i a la discusió de la forma i del contingut d'una de les obres més importants de Ramon Llull: el Llibre de contemplació en Déu. Sota el títol «Gottes Schau und Weltbetrachtung. Interpretationen zum Liber contemplationis des Raimundus Lullus» («Visió de Déu i contemplació del món. Interpretacions sobre el Llibre de contemplació de Ramon Llull») es van discutir diversos aspectes d'aquest text des de múltiples camps i punts de vista. Les sessions van tenir lloc a la «Katholische Akademie» de l'arxidiòcesi de Freiburg, institució que a més d'acollir l'event va participar en la seva organització.

El tema elegit, una única obra de Llull, no és cosa nova. Deu anys abans el «Raimundus-Lullus-Institut» ja va celebrar una altra trobada amb ocasió del seu 40 aniversari, aleshores dedicada a un altre títol fonamental en el catàleg lul-lià: 1'Arbor scientiae. ${ }^{1}$ Aquest cop els organitzadors han triat el Llibre de contemplació tant per la innegable importància de l'obra en el conjunt de la producció de l'autor com per ser un dels títols en l'edició crítica del qual s'està treballant en aquests moments. La seva extensió, la multiplicitat de temes que s'hi tracten, amb un tarannà quasi enciclopèdic (com era el cas també de l'Arbor

\footnotetext{
${ }^{1}$ Fernando Domínguez Reboiras, Pere Villalba Varneda i Peter Walter (eds.), Arbor scientiae. Der Baum des Wissens von Ramon Llull. Akten des Internationalen Kongresses aus Anla des 40-jährigen Jibuläums des Raimundus-Lullus-Institut der Universität Freiburg i. Br., Turnhout, Brepols (Subsidia Lulliana 1), 2002.
} 
scientiae), el fan atractiu per a un acostament multidisciplinar com el que planteja el congrés. Es tracta d'una obra immensa, organitzada en 365 capítols més un de conclusiu (un capítol per cada dia de l'any) i estructurada segons una fèrria composició numericosimbòlica. Suposa un primer intent per part de Llull de sistematitzar un mètode de contemplació amb aplicacions diverses en els àmbits científic, apologètic, moral, etc., però sempre partint - i tornant- al nucli central, que és conèixer i estimar Déu.

La multiplicitat d'acostaments al text va dur els organitzadors a plantejar un programa igualment variat, no només pel que fa als temes proposats, sinó també en allò referit als intervinents. Es va optar explícitament per reduir el nombre d'experts en l'obra de Llull en general a favor d'una presència significativa d'experts de reconegut prestigi en els temes tractats. L'objectiu era clar: veure què poden aportar a la interpretació del text lul-lià estudiosos «de fora» de l'àmbit específic del lul-lisme. El resultat fou, en efecte, sorprenent en alguns casos, en el sentit positiu del terme. Que l'obra de Llull s'ha de contemplar des del seu context cultural, malgrat la seva especificitat (precisament, per tal d'entendre millor aquesta especificitat) és una cosa que els que ens encarreguem d'estudiar-la ja tenim clar. Però per superar efectivament la imatge d'un Llull aïllat en la seva diferència convé incorporar l'estudi d'aquesta obra als cercles «normals» acadèmics dedicats a la filosofia i a la història medievals.

Aquesta ha estat la premissa del congrés. Òbviament, també es van aplegar a les sessions de la Katholische Akademie experts lul-listes. Com a conferenciants pocs; més com a públic participatiu que, al final les ponències, va promoure debats, discussions, intercanvi d'idees. Cosa cada vegada més difícil de trobar en els aplecs científics a l'ús entre els «humanistes». En aquest cas, però, la situació es prestava, com va quedar clar des de les primeres sessions, dedicades a la problemàtica que planteja l'edició del text i les relacions entre les versions llatina i catalana.

Jordi Gayà, rector de la «Maioricensis Schola Lullistica» i l'encarregat de l'edició crítica del text llatí per a les ROL, va oferir algunes dades molt interessants a partir de la comparació del mateix amb la versió catalana original. La traducció llatina (pel que sembla, feta sota el control directe de l'autor) modifica subtilment alguns passatges per tal d'aportar més rigor teològic al vocabulari emprat. L'estudi exhaustiu del manuscrit llatí París BN 3448A, fet per la següent ponent, la professora Gabriela Pomaro, també va donar moltes pistes sobre el procés de redacció d'un text tan complet -i tan complex. A partir d'ací, un tema semblava tornar un i altre cop en els debats amb què van concloure les ponències, a manera de leitmotiv de les jornades: el del sentit atorgat per Llull a determinats conceptes el significat dels quals és clar en el seu context filosòfic, però que en el nostre autor pren una deriva diferent a l'esperada. Els experts «externs» al lul-lisme i coneixedors de la filosofia medieval van arribar a parlar de «sorpresa» davant el Llibre de contemplació. El text no era com s'havien esperat. I l'ús específicament lul-lià del vocabulari filosòfic fa difícil interpetar el seu pensament.

Sembla doncs que, després de set-cents anys, Ramon Llull continua sorprenent l'àmbit acadèmic oficial, com ja ho va fer a París, per exemple, 
l'any 1289, arran de les lliçons sobre l'Ars que hi va impartir personalment. Aquesta capacitat inesgotable de provocar sorpresa es pot prendre en un sentit tant negatiu com positiu. N'hi hagué durant el congrés per a tots els gustos. Des de qui va expressar en termes de «catàstrofe» el trasbalsament lul-lià del lèxic filosòfic que trenca amb la tradició intel-lectual, fins qui va invocar el ja famós «Lullum, antequam Lullum noscas, ne despicias», del judici que el metge Andreu Oliver va incorporar a l'edició mallorquina de 1752 dels tractats lul-lians sobre medicina.

Benvinguda sigui aquesta trobada, i d'altres com aquesta, si pot servir perquè Llull sigui més conegut -i estimat. Per aconseguir-ho, potser caldrà vèncer encara algunes reticències. I agafar la sorpresa en sentit positiu, com a esperó per aprofundir en un pensament marcat per l'originalitat de les seves propostes. Una originalitat que, amb tot, no pot negligir el diàleg de Llull amb la tradició. I aquest és un altre punt destacat a les sessions del congrés. Els ressons franciscans en l'expressió de l'alegria com a tema inicial del llibre (Thomas Ricklin, Múnic), la tradició teològica dels «noms de Déu» darrere la presentació de les propietats divines (Annemarie Mayer, Tübingen), les connexions de la contemplació lul-liana amb les tradicions místiques (Alois Haas, Zürich)... Aquests i molts d'altres temes van protagonitzar les sessions, des de l'òptica aportada pels experts. Personalment, vaig trobar d'allò més ric la contemplació del text de Llull des del punt de vista extern, el que aporta una perspectiva que difícilment podem adoptar els qui estem massa habituats a l'obra de Llull. ${ }^{2}$

Recuperar la capacitat de sorpresa davant el Llibre de contemplació: aquest podria ser un bon propòsit per a després de les jornades. I una actitud que podria afavorir l'aprofundiment progressiu en els seus sentits. Cal estar disposat a veure'l amb una mirada diferent. Començant per l'estructura mateixa de l'obra, marcada per una arquitectura simboliconumèrica que cal reinterpretar. Almenys així m'ho sembla, després d'escoltar la ponència de Viola TengeWolf i el subsegüent debat.

A banda de les qüestions filosòfiques i teològiques es van tractar aspectes històrics, com la relació del Llibre de contemplació amb la missió i la croada (tema desenvolupat per una autoritat en la matèria, el professor Franco Cardini). En definitiva, el programa presentava un recorregut temàtic exhaustiu per l'obra a partir de la dissecció de la mateixa en grups de capítols sobre els quals cada intervinent havia d'aplicar la seva pròpia i lliure exègesi. El plantejament es mostrà fructífer, ja que aquest acostament polièdric a diverses interpretacions del llibre a partir dels seus blocs temàtics va donar lloc, finalment, a una visió de conjunt més unitària del que es podria pensar en un inici, si tenim en compte que en els debats es teixien fils de connexió entre els diversos aspectes tractats per separat a les ponències.

Com és obligat en els congressos, també en aquest els organitzadors van saber incorporar el necessari espai per a la trobada més distesa entre els

${ }^{2}$ El programa complet del congrés, amb el nom dels intervinents i els títols de les ponències, és accessible «on line» a l'adreça http://www.mediaevalsophia.it/OSMILL/Lullo\%20Freiburg.pdf 
assistents. L'ocasió, a més, ho exigia especialment: el dimarts 27 de novembre, festa del beat Ramon Llull, va haver-hi un sopar festiu amenitzat amb tots els complements propis de les efemèrides. Perquè es festejava el beat, però també, no ho oblidem, els 50 anys de l'institut que n'edita l'obra llatina. Personalitats del més alt nivell de la Universitat de Freiburg, de l'Arquebisbat, de l'Institut d'Estudis Balears, del Patronat Ramon Llull per a l'edició de l'obra catalana -i també de l'editorial Brepols- hi van ser presents. Com a cloenda de les sessions, Fernando Domínguez Reboiras va fer un balanç dels cinquanta anys d'història del Raimundus-Lullus-Institut; un balanç que, en bona mesura, és el de la seva aportació a la tasca acadèmica de la institució, ja que ha sigut durant més de la meitat d'aqueix temps l'ànima de l'edició de les ROL. Després de la seva recent jubilació la tasca continua, i el Raimundus-Lullus-Institut camina cap al futur. D'aquest futur va tractar l'altra ponència de cloenda, la del seu director, el professor Peter Walter.

No hi ha dubte, doncs, que Ramon Llull és el més internacional dels autors catalans. 